\title{
Topo $2 \alpha$ protein expression predicts response to anthracycline combination neo-adjuvant chemotherapy in locally advanced primary breast cancer
}

\author{
A Mukherjee ${ }^{\text {I,2, M Shehata', P Moseley', E Rakha' }{ }^{2} \text { I Ellis }{ }^{2} \text { and S Chan }}{ }^{*, I}$ \\ 'Department of Oncology, Nottingham University Hospitals, City Hospital Campus, Hucknall Road, Nottingham, NG5 IPB, UK; \\ ${ }^{2}$ Department of Pathology, Nottingham University Hospitals, City Hospital Campus, Hucknall Road, Nottingham, NG5 IPB, UK
}

BACKGROUND: This study aimed to identify predictors of response to anthracycline-based chemotherapy (5-fluoro-uracil, epirubicin, cyclophosphamide (FEC)) in locally advanced primary breast cancer (LAPC).

METHODS: A total of 9I LAPC patients were treated with six cycles of FEC before surgery. Protein expression of nine biomarkers (topoisomerase2 $\alpha$ (Topo2 $\alpha$ ), ER, PR, HER2, Ki67, p53, EGFR, CK5/6 and CK14) was assessed in pre-chemotherapy core biopsies using immunohistochemistry $(\mathrm{IHC})$ and results correlated with clinical and pathological response.

RESULTS: Clinical (cCR) and pathological (PCR) complete response were seen in 34.1\% $(n=31)$ and $20 \%(n=\mid 8)$, respectively. Pathological complete response was concordant with CCR in $|4 / 3|$ cases; in four cases of $\mathrm{CPR}$ with palpable residual breast tumours, histology showed fibrous tissue only $(\mathrm{pCR})$. On univariate analysis, pre-chemotherapy high expression of Topo $2 \alpha$ protein $(P=0.03 \mathrm{I})$, and negativity for ER and EGFR $(P=0.001$ and $P=0.005$, respectively) correlated with $p C R$. Positivity for $p 53$ also showed significance $(P=0.015)$, whereas basal phenotype, HER2, and all the clinicopathological variables of LAPC included in this study did not show significant correlation with response. On multivariate analysis, Topo $2 \alpha$ expression had the strongest correlation with $\mathrm{pCR}$ $(P=0.021)$ followed by EGFR $(P=0.044)$.

CONCLUSION: The study suggests that pre-chemotherapy Topo $2 \alpha$ protein expression measured by $H \mathrm{HC}$ strongly correlates with pathological CR to neo-adjuvant anthracyclines in this group of LAPC studied.

British Journal of Cancer (2010) 1 03, 1794- 1800. doi:10.1038/sj.bjc.6605960 www.bjcancer.com

Published online 9 November 2010

(c) 2010 Cancer Research UK

Keywords: biomarkers; neo-adjuvant therapy; breast cancer

Neo-adjuvant chemotherapy is an established treatment modality for locally advanced primary breast cancer (LAPC) (Mieog et al, 2007). It aims to reduce the size of the primary tumour, to enable complete surgical removal of the primary tumour and axillary lymph-node metastases, and in smaller/earlier tumours it may allow breast conservation and other oncoplastic options without compromising tumour control. In addition, serial biopsies taken during neo-adjuvant chemotherapy offers the chance of individualization of therapy by offering the scope of evaluating early molecular changes of various biological or pathological markers predictive of response or resistance.

The optimal neo-adjuvant combination for the individual patient is a worthy research question. Anthracycline-based regimens are commonly used because it is one of the most effective in this setting. The reported clinical (cCR) and pathological (pCR) complete response rates for anthracycline alone and anthracycline combination regimes are in the range of $30-40 \%$ and $13-26 \%$, respectively (Mieog et al, 2007). Furthermore, there are about $5 \%$ of breast cancers, which are resistant (have clinically progressive disease) to neo-adjuvant anthracycline chemotherapy. In these

*Correspondence: Dr S Chan; E-mail: steve.chan@nuh.nhs.uk Received 24 May 2010; revised 24 September 20l0; accepted 24 September 2010; published online 9 November 2010 cases, unnecessary side effects such as cardio-toxicity may be avoided if biomarkers of response are identified.

Integral to the action of anthracyclines is the inhibition of topoisomerase $2 \alpha$ (Topo $2 \alpha$ ). This subclass of topoisomerase binds DNA and forms transient double-stranded breaks in replicating DNA, allowing passage of a second DNA double-helix strand. Inhibition of Topo $2 \alpha$ leads to double-strand DNA breaks and cell death (reviewed by Di Leo et al, 2008). Previous studies have demonstrated that Topo $\alpha$ is a predictor of response to anthracycline-based therapy (MacGrogan et al, 2003; Durbecq et al, 2004). However, other studies have indicated that other markers such as HER2 (Sánchez-Muñoz et al, 2008) or basal phenotype (BP) (Rakha et al, 2008) may provide predictor information. Proliferation as assessed by Ki67 has also been shown to correlate with outcome (Bozzetti et al, 2006). Therefore, in this study we assessed the predictive value of multiple molecular biomarkers in a series of 91 patients presenting with LAPC who had been offered anthracycline-based therapy.

\section{MATERIALS AND METHODS}

\section{Patient treatment profile}

A total of 91 patients presenting with LAPC between December 1996 and December 2009 at our institution and treated with 
neo-adjuvant anthracycline-based chemotherapy were included in this study. A core biopsy was performed before the chemotherapy treatment to allow a pathological diagnosis and evaluation of biological parameters. Patients were treated with the following regimen.

Six cycles of an anthracycline-based therapy (FEC: 5-fluorouracil (5-FU) $500 \mathrm{mg} \mathrm{m}^{-2}$, epirubicin $75-100 \mathrm{mg} \mathrm{m}^{-2}$, cyclophosphamide $500 \mathrm{mg} \mathrm{m}^{-2}$, on day 1 of a 21 -day cycle). Patients were scheduled to undergo surgery 4 weeks after the sixth cycle.

\section{Assessment of response}

Assessment of the tumour response was undertaken by clinical measurements both before chemotherapy treatment and after each cycle of chemotherapy. The clinical baseline and preoperative measurements were obtained with a calliper by the same clinician or by radiological assessment. Clinical response was recorded according to RECIST criteria (Park et al, 2003a).

The pathological response was evaluated by histological examination of tumour removed following chemotherapy. The surgical procedures that were performed included the following: Simple mastectomy (13.7\%), Patey mastectomy $(82.9 \%)$ and wide local excision (3.4\%). Histology including grade was reviewed and agreed upon by two experienced breast pathologists utilising the Chevallier classification: the absence of invasive tumour cells or persistence of only in situ disease, and negative axillary lymph nodes define a pathological CR (Chevallier et al, 1993). On an average, 16 breast blocks and all submitted lymph nodes (in entirety) were examined for each case before a diagnosis of pCR was reached.

\section{Immunohistochemistry techniques for biomarkers}

Immunohistochemistry was done on core biopsies (pre-treatment) with the use of a standard avidin-biotin peroxidase technique (Madjd et al, 2003). Heat-induced epitope retrieval consisting of 20 -min microwave treatment $(10 \mathrm{~min}$ at high power and $10 \mathrm{~min}$ at low power) in $\mathrm{pH} 6.0$ citrate buffer was necessary for all markers, except HER2. For Ki67 staining, sections were treated with $10 \%$ trypsin before heat-induced antigen retrieval. Sources and dilution of primary antibodies are summarised in Table 1.

\section{Evaluation of staining}

Two observers, blinded to the clinicopathological data, evaluated the staining for consensus. Cut-off values for scoring are summarised in Table 1 . The cut-off values were chosen as per standards peer-reviewed and well accepted in literature
(Rakha et al, 2006, 2007). For Topo $2 \alpha$, the median was chosen as the cut-off for high and low staining as the data distribution is not homogeneous (Supplementary Figure 1).

\section{Statistical analysis}

Statistical analysis was performed using SPSS17 statistical software (SPSS Inc., Chicago, IL, USA). Pearson's $\chi^{2}$-tests were used to determine the significance of associations between categorical variables. Overall survival (OS) calculations included all patients who died during follow-up. Survival rates were calculated using the Kaplan-Meier method; differences between groups were tested using the log-rank test. Events for relapse-free and OS were defined as follows: time of disease relapse, either local or distant (for relapse-free survival), and time of death, (for OS), respectively. The Cox proportional-hazards model was used for multivariate analysis in order to determine the relative risk and independent significance of individual factors. In all cases two-sided $P$-values of $<0.05$ were considered as statistically significant.

\section{RESULTS}

\section{Clinicopathological characteristics}

The mean age of the patients was 51 years (range 25-76 years). Histologically, the tumours were classified as follows: Ductal NST $83(91.2 \%)$; lobular $(8.8 \%)$. The tumours were T's taged as follows: T2 14 (15.6\%); T3 72 (79.2\%); T4 5 (5.2\%). Four of these were inflammatory breast cancers. The grades of the tumours were as follows: G1 1 (1\%); G2 40 (44\%); G3: 50 (55\%). The N-stage for such cases treated by neo-adjuvant therapy may not be very accurate as it is based on clinical examination and not all palpable lymph nodes may be involved by tumour. Hence this was not included in the paper. By definition, the $M$ status of locally advanced breast cancer patients is $\mathrm{M}_{0}$ and this was confirmed in the current series.

The characteristics of the tumours analysed by IHC are summarised in Table 2 .

\section{Response to chemotherapy regimens}

The overall response to anthracycline combination was as follows: cCR 31 (34.1\%); cPR 42 (46.2\%) (cORR 80.3\%); cSD 15 (16.4\%); cPD 3 (3.3\%). Pathological complete response was observed in 18 patients (20\%). Clinical CR conformed to pCR in 14 cases; in 4 cases of clinical partial response, histology showed fibrous tissue only (pCR).

Table I Source, dilution and cut-off values for positivity for different biomarkers

\begin{tabular}{|c|c|c|c|c|}
\hline Marker & $\begin{array}{l}\text { Antibody } \\
\text { (Source) }\end{array}$ & $\begin{array}{l}\text { Optimal } \\
\text { dilution }\end{array}$ & $\begin{array}{l}\text { Positive-control } \\
\text { tissue }\end{array}$ & Cut-off values for positivity \\
\hline ck5/6 & $\begin{array}{l}\text { D5/I } 6 \text { B4 (Dako UK Ltd, Ely, } \\
\text { Cambridgeshire, UK) }\end{array}$ & $1: 100$ & Tonsil & $10 \%$ \\
\hline $\mathrm{ck} \mid 4$ & $\begin{array}{l}\text { LL002 (Vector Labs, } \\
\text { Peterborough, UK) }\end{array}$ & $1: 100$ & Skin & $10 \%$ \\
\hline ER & ID5 (Dako UK Ltd) & $1: 100$ & Breast & $1 \%$ \\
\hline PGR & PGR 636 (Dako UK Ltd) & Neat & Breast & $1 \%$ \\
\hline HER2 & DakoA0485 (Dako UK Ltd) & $1: 500$ & Breast & 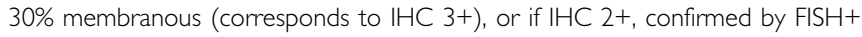 \\
\hline p53 & DO7 (Dako UK Ltd) & $1: 100$ & Breast & I0\% nuclear \\
\hline EGFR & EGFR. I I 3 (Dako UK Ltd) & $1: 50$ & Skin & I0\% membranous \\
\hline Topo $2 \alpha$ & KI-SI (Dako UK Ltd) & $1: 100$ & Tonsil & $45 \%$ nuclear (high) \\
\hline $\mathrm{K} 167$ & MIBI (Dako UK Ltd) & $1: 100$ & Tonsil & I0\% nuclear (high) \\
\hline
\end{tabular}

Positive-control tissue is also indicated. Positive HER2 was defined as presence of membrane expression of the protein in $>30 \%$ of tumour cells (corresponds to $I \mathrm{HC} 3+$ ) or if underexpressed $(2+)$, confirmed by FISH (fluorescent in situ hybridisation). For p53, Topo $2 \alpha$ and Ki67, 100 nuclei were scored for positivity in four random fields ( $\times 40$ magnification) and the total percent-score obtained. Median values of Topo $2 \alpha$ were chosen as cut-offs for high or low expression. Other standard cut-offs as per Rakha et al (2006, 2007) 
Table 2 Immunohistochemistry analysis and correlations with $\mathrm{PCR}$ for patients treated with anthracyclines

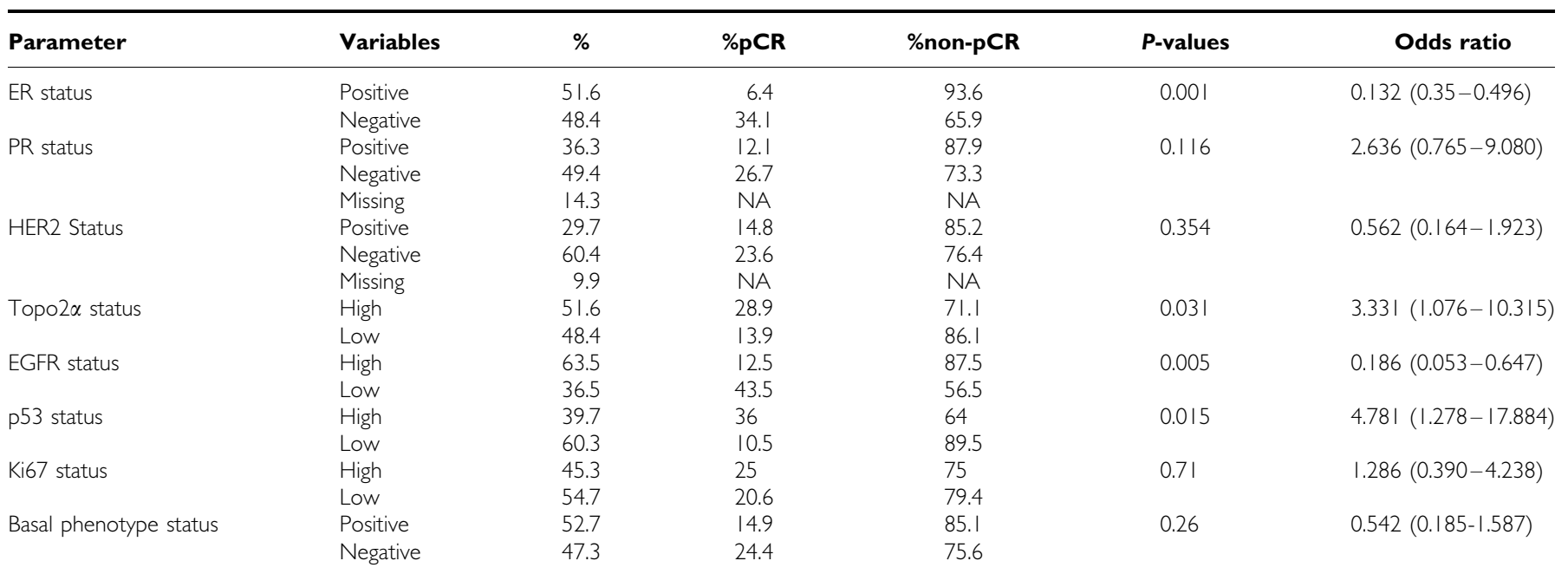

Abbreviation: not applicable. The columns for \% pCR and \% non-pCR show the response in each category of immunohistochemical variable (positive/negative; high/low). The Pearson's $\chi^{2}$-significance is presented in the P-value column. The Odds ratios with $95 \%$ confidence intervals are shown in brackets.

\section{Biomarker expression}

Immunohistochemistry results. The relationship of immunohistochemical markers and pCR are summarised in Table 2 (and Supplementary Table2). On univariate analysis, the following biomarkers correlated with pCR to anthracyclines: Pre-chemotherapy high Topo $2 \alpha$ expression $(P=0.031)$, ER - $(P=0.001)$, EGFR $-(P=0.005)$ and p53 $+(P=0.015)$. Patient age $(P=0.65)$, tumour size $(P=0.7)$, histological subtype $(P=0.58)$, tumour grade $(P=0.112)$, HER2 status $(P=0.354)$, progesterone receptor status $(P=0.116)$ and Ki67 $(P=0.71)$ did not predict response to anthracycline-based therapy. There was no correlation between Topo $2 \alpha$ protein expression and HER 2 protein expression in the examined series $(P=0.692)$. Neither was there any correlation between Topo $2 \alpha$ and Ki67 $(P=0.9)$ in this study.

For this study, the BP was defined as immuno-phenotypic evidence of basal cytokeratins CK5/6 and/or CK14 expression $(>10 \%)$ (Rakha et al, 2006). The BP was highly expressed in 48 patients $(52.7 \%)$. The BP status was not significant for response to neo-adjuvant chemotherapy $(P=0.26)$. When defined as $\mathrm{BP}$ and $\mathrm{EGFR}+$, the incidence of the BP is $23.9 \%$; this was also not significant for response to neo-adjuvant chemotherapy $(P=0.5)$ (Nielsen et al, 2004). In all, $44 \%$ of the BP + cases are p53 positive. This is however not statistically significant. The incidence of triple-negative cancers in the series is $24.1 \%$.

Multivariate analysis was conducted including ER status, EGFR status, p53 and Topo $2 \alpha$ protein status as variables in the regression equation. Topo $2 \alpha$ protein expression correlated with pCR $(P=0.021$; estimated HR: 6.587; 95\% confidence intervals (CI): 1.327-32.707; of the other variables, EGFR - status was also significant ( $P=0.044$; estimated HR; $4.765 ; 95 \%$ CI: $1.045-21.729)$. Both ER $(P=0.64)$ and p53 $(P=0.422)$ failed to achieve significance.

\section{Survival analysis}

Pathological complete response for the series correlated with better relapse-free $(P=0.005)$ and $\mathrm{OS}(P=0.006)$ (Figure $1 \mathrm{~A}$ and $\mathrm{B}$ ). A total of 31 patients included in this study had relapsed after their neo-adjuvant chemotherapy; the median follow-up was 62 months. A total of 21 patients have died from breast cancer during the period. The estimated mean RFS for those who achieved pCR was 140 months. For those who had progressive disease, the estimated median OS was 7 months.
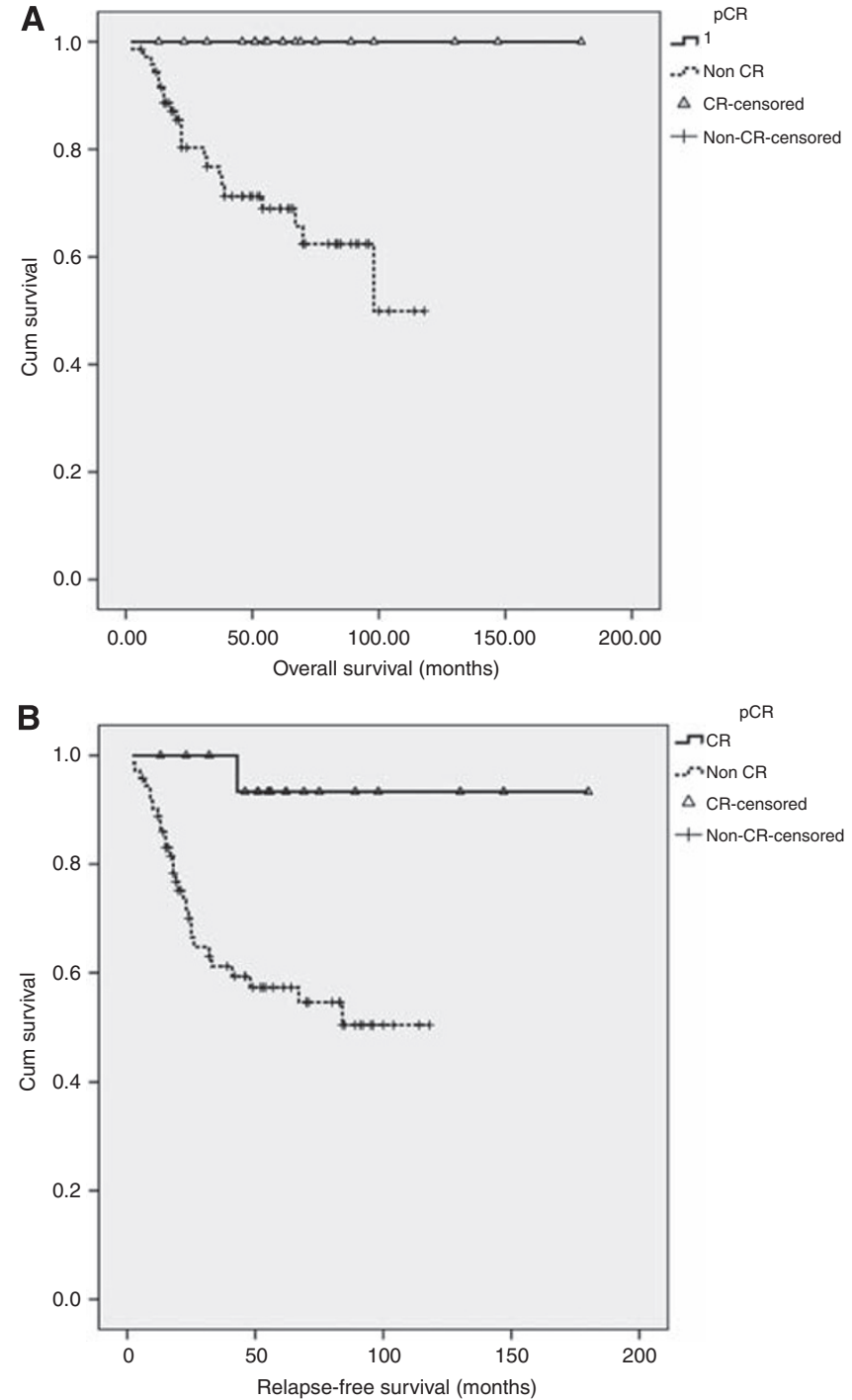

Figure I Overall survival $(\mathbf{A})$ and relapse-free survival (B) analysis for patients with $p C R$ and non-pCR to anthracyclines. 

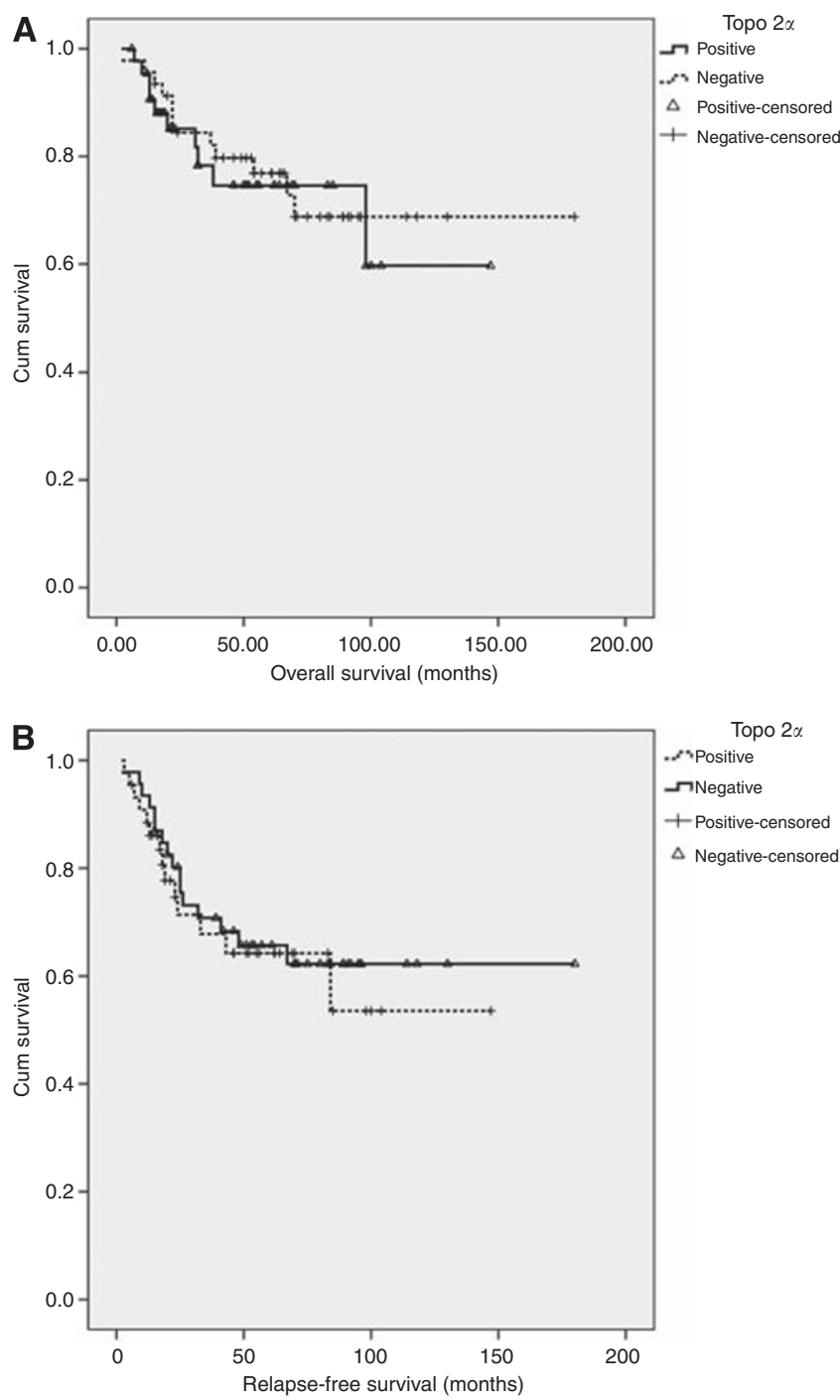

Figure 2 Overall survival $(\mathbf{A})$ and relapse-free survival $(\mathbf{B})$ analysis for patients with low and high Topo $2 \alpha$ protein levels.

Of the relapses and deaths, $19(61 \%)$ and $10(47 \%)$ were Topo $2 \alpha-$ high, respectively. However, Topo $2 \alpha$ status did not predict either relapse-free $(P=0.67)$ or $\mathrm{OS}(P=0.76)$ (Figure $2 \mathrm{~A}$ and $\mathrm{B}$ ). Similarly, although patients with BP tumours tend to have a worse OS and RFS, this was not statistically significant $(P=0.5$ and $P=0.54$, respectively) (Figure $3 \mathrm{~A}$ and $\mathrm{B}$ ).

\section{DISCUSSION}

Neo-adjuvant chemotherapy for patients with LAPC has been shown to increase surgical resectability and breast conservation rates (Mieog et al, 2007). A unique advantage of primary chemotherapy is the possibility to take serial measurements and biopsies of the primary tumour, thus allowing an in vivo assessment of factors predictive of response or resistance to treatment.

The use of anthracycline regimen in the adjuvant setting has reduced mortality due to breast cancer (Cardoso and Piccart, 2003), but significant cardiac toxicity leading to congestive cardiac failure has been reported in $3.7 \%$ of patients treated with doxorubicin (Chan et al, 1999). It is clear that the use of the drug

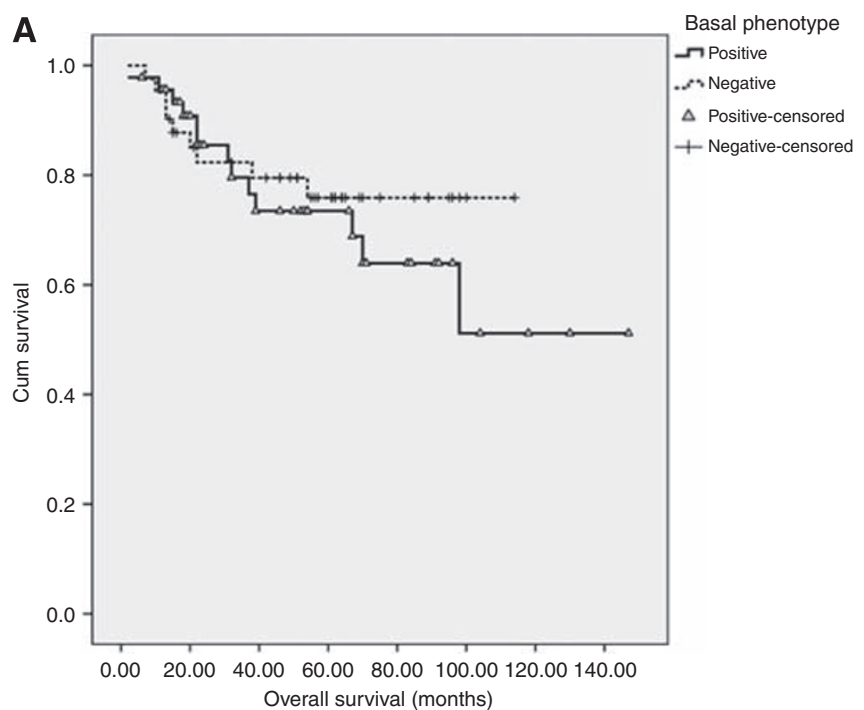

B

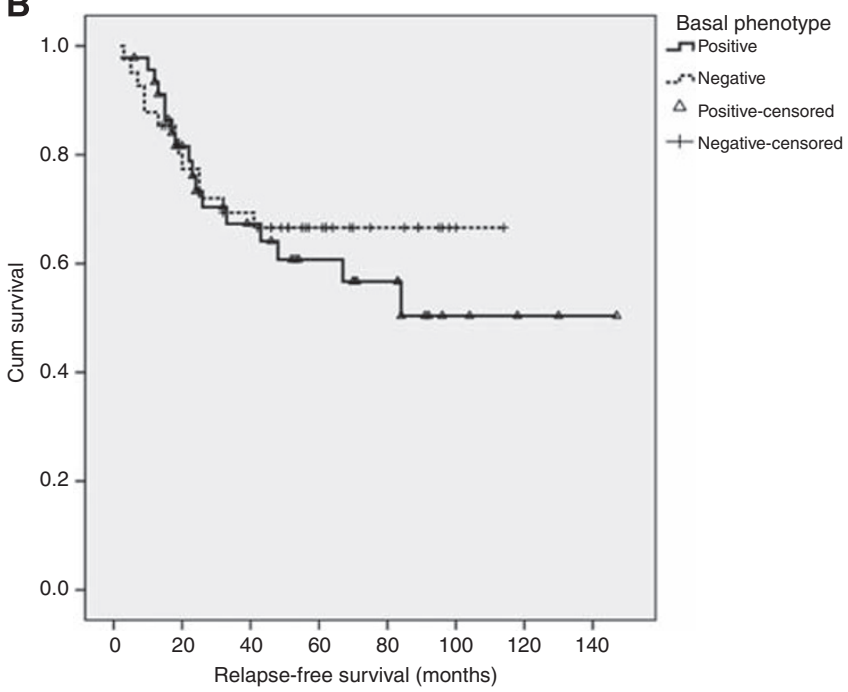

Figure 3 Overall survival $(\mathbf{A})$ and relapse-free survival $(\mathbf{B})$ analysis for patients either positive or negative for basal phenotype (BP).

should be avoided in resistant tumours. Hence, the search for biomarkers predictive of resistance to neo-adjuvant anthracycline containing regimes is important.

Pathological complete response is the most reliable end-point of response to neo-adjuvant treatment and hence was chosen in this study. Pathological complete response for the series correlated with better OS. Factors associated with pCR on univariate analysis include Topo $2 \alpha$, EGFR, ER and p53.

The evidence in literature for and against Topo $2 \alpha$ as a marker for response to anthracyclines is variable. The main role of Topo $2 \alpha$ has been explored as a prognostic and predictive biomarker for anthracyclines in the adjuvant setting and the results thus have been far contradictory. This study is unique in that it deals with a pure cohort of patients of locally advanced breast cancer who did not have any treatment (surgery, radiotherapy, chemotherapy or hormonal therapy) before anthracycline chemotherapy.

This study evaluated Topo $2 \alpha$ protein expression as adjudged by IHC. Previous studies looking at anthracyclines and Topo $2 \alpha$ have utilised different end-points viz. gene expression or protein analysis. Topo $2 \alpha$ is regulated at multiple levels, viz. at the gene level (amplification and deletion), post-translational mechanisms such as mRNA stabilisation, subcellular protein distribution and 
isoform expression. Immunohistochemistry evaluation of Topo $2 \alpha$ though criticised as being semi-quantitative is a holistic end-point. Protein expression summates the net-effects of gene translational and proliferation controls, and hence was chosen for this study. Only nuclear staining was considered positive, taking into account the active subcellular location. Tumour-proliferation status is known to have a key role in regulating Topo $2 \alpha$ protein levels, independently of Topo $2 \alpha$ gene status (Di Leo et al, 2008). In our series, however, no correlation was observed between Topo $2 \alpha$ and Ki-67 protein levels and differential chemosensitivity does not appear to be simply a function of the proliferation status of the tumour. It is important to stress here that the LAPC cohort represents a highly selected population with most tumours being either grade $2 / 3(98 \%)$ and having a high proliferation index (79\% with Ki67 >10\%).

Our results showed that Topo $2 \alpha$ protein as measured by IHC in pre-chemotherapy tumours strongly correlates with pCR. This concords with the results reported previously (MacGrogan et al, 2003; Martin-Richard et al, 2004) that show that the response to neo-adjuvant chemotherapy was correlated with the IHC expression of Topo $2 \alpha$. Recent reports in the adjuvant setting also confirm that Topo $2 \alpha$ protein rather than gene expression correlates with response to anthracycline-based therapy (Schindlbeck et al, 2010). Park et al (2003b) reported a good response to doxorubicin in breast cancers with co-amplification of HER2 and Topo $2 \alpha$ (as measured by chromogenic in situ hybridisation) and in HER2-amplified tumours with or without Topo $2 \alpha$ amplification. Co-amplification of HER2 and Topo $2 \alpha$ also correlated with response to anthracycline-based therapy in a series of high-risk primary breast cancers (Konecny et al, 2010). In our studies, there was no correlation between HER 2 and Topo $2 \alpha$ expression as measured by IHC, and HER2/Topo $2 \alpha$ co-expression on a protein level did not correlate for response to anthracyclines. Recent reports from the MA.5 trial show that Topo $2 \alpha$ protein overexpression is not closely correlated to HER2 positivity but is a significant predictor of differential response to anthracycline combination chemotherapy (O'Malley et al, 2006). This study did not preselect for HER2-positive patients treated with anthracyclines. We concur with the view that the 'jury is still out' over this issue with both proponents and opponents for such selection (Esteva and Hortobagyi, 2009).

The predictive value of Topo $2 \alpha$ protein levels in the neoadjuvant setting in locally advanced breast cancer parallels other retrospective studies in early or advanced breast cancer. In the adjuvant setting, a dose-intense anthracycline-based chemotherapy showed superiority over a less intensive regimen only in the cohort of patients carrying Topo $2 \alpha$ protein overexpression (Di Leo et al, 2001). Results from a retrospective phase III clinical trial conducted by the National Cancer Institute - Canada Group also confirm that Topo $2 \alpha$ protein overexpression might be associated with increased benefit from doxorubicin (hazard ratio 1.09, 95\% CI: 1.03-1.15, $P=0.002$ ) (Durbecq et al, 2004).

The prospective TOP trial that was specifically designed to identify markers of response/resistance to preoperative epirubicin in oestrogen receptor-negative breast cancer patients, showed that Topo $2 \alpha$ amplification (as identified by FISH) was exclusively observed in HER2-amplified cases and was highly predictive of pCR (Desmedt et al, 2009). In contrast to this study, protein levels were not predictive of pCR. In another small series of 23 patients with endocrine unresponsive and HER2-overexpressing tumours, Topo $2 \alpha$ amplification correlated with a significantly high probability of achieving pCR after neo-adjuvant, anthracycline-based chemotherapy (Orlando et al, 2008).

In spite of being correlated with pCR, Topo $2 \alpha$ protein levels did not show any particular trend in the cases that had progressive disease. Notwithstanding the small number of cases with progressive disease, it appears that although the Topo $2 \alpha$ level predicts for response, it does not automatically predict for the most resistant. Tumour resistance depends on complex interaction of multiple factors. Similarly, the lack of significant correlation between overall or progression-free survival withTopo $2 \alpha$ may also be attributed to the interplay of multiple factors.

Apart from Topo $2 \alpha$, the EGFR - status was predictive of pCR in univariate and multivariate analysis in this study. In other studies, EGFR-negative tumours had a better OS following neo-adjuvant anthracyclines but did not predict for pCR (Buchholz et al, 2005 and Schippinger et al, 2007). The association of the EGFR- status with pCR in this study may be explained by the downstream signaling pathways activated by EGFR signaling resulting in resistance to chemotherapy-induced apoptosis.

In our study, the ER negative status is an indicator of response to anthracyclines on univariate analysis. In a larger series of 485 patients with LAPC (cT2-T4, N0-2, M0) ER/PR - tumours were 12 times more likely to achieve a pCR to anthracyclines $(P<0.0001)$ (Colleoni et al, 2008). Thus the ER negative status may be an indication of response to pre-operative chemotherapy in LAPC.

The p53 is a known tumour suppressor and the nuclear protein has an essential role in the regulation of cell cycle. Breast cancer patients with p53 mutations or protein accumulation have been shown to have worse survival (Miller et al, 2005). Pathological complete response was associated with overexpressed p53 in our series, as reported in other studies (Colleoni et al, 1999; Faneyte et al, 2003; Mieog et al, 2006). Recent findings (Bertheau et al, 2007) indicate that non-inflammatory breast tumours containing mutant TP53-in particular, basal-cell-like tumours-are very sensitive to dose-dense epirubicin and cyclophosphamide chemotherapy. The correlation between positive p53 and response has been explained by the dose-dense regime used in the study. Other authors (Faneyte et al, 2003) have tried to explain the association of p53 + state with pCR with the following hypothesis: possibly, the DNA damage that is initially tolerated by cells with mutated p53 (positive on IHC) decreases viability during subsequent tumour proliferation. In contrast, with intact p53 (negative on IHC), DNA repair mechanisms rescue cancer-cell viability. It must be remembered that the correlation between p53 protein accumulation and the presence of mutations is not absolute and hence, IHC results must be interpreted with caution.

A recent progress into the molecular classification of breast cancer includes the BP, originally identified from its geneexpression profile. Our study used the stated definition of the BP and found a high propensity of the cytokeratins in our LAPC tumours. The high incidence probably reflects the highly selected group of locally advanced breast cancers, which might have an incidence of BP different from the whole breast cancer population. It is sometimes perceived that BP tumours and triple-negative tumours are synonymous and BP can be defined using a triplenegative definition without the need for the expression of basal markers. However, contrary to popular belief, it has been shown that triple-negative tumours are a heterogeneous population that may either be basal cytokeratin-positive or basal cytokeratinnegative (Rakha et al, 2009). Hence, the basal cytokeratin-based definition that has been widely used in the literature (Rakha et al, 2006, 2008) and in this study is probably more relevant in the authors' opinion.

As for response to anthracycline-based chemotherapy, the BP status did not predict response/resistance to anthracyclines in our series. The response of basal-like tumours to chemotherapy is not well-defined (Rouzier et al, 2005; Rodríguez-Pinilla et al, 2006; Banerjee et al, 2006; Tan et al, 2008). In one study (Carey et al, 2007), the basal-like and HER2 subtypes, defined by hormone receptor IHC only, had the highest rates of PCR to pre-operative anthracycline-based chemotherapy, whereas the luminal tumours responded poorly. Paradoxically, despite the significantly higher prevalence of pCR in the basal-like group, patients with these tumours still displayed the worst outcome. These discrepancies 
might reflect differences in defining the $\mathrm{BP}$, chemotherapy regimens or patient populations studied, protein expression $v s$ gene profiling, as well as the molecular heterogeneity of basal breast tumours. As for overall and progression-free survival, the $\mathrm{BP}+-$ cohort tends to fare worse. The $\mathrm{BP}+$ group inherently defines cancers of a bad prognostic group, documented well in the literature.

This study concludes that high Topo $2 \alpha$ is the biomarker that has the strongest correlation with PCR to neo-adjuvant anthracycline combination. The strength of this study is the fact that these patients had no previous cancer treatment, therefore the pCR rate can be directly attributed to the FEC chemotherapy. Furthermore, a battery of biomarkers were examined concurrently with Topo $2 \alpha$ and preselection based on HER2 status, was avoided. Given the controversies surrounding the best and most accurate way to assess the Topo $2 \alpha$-gene expression, the authors suggest that the protein level, as determined by IHC, is an easily available as well as summative end-point that should not be disregarded in future studies. Further proteomic fine-tuning of quantitative analysis for Topo $2 \alpha$ protein levels may help clinicians tailor their selection of chemotherapeutic agent for neo-adjuvant treatment. The alkylating agent administered with the anthracyclines may also be a

\section{REFERENCES}

Banerjee S, Reis-Filho JS, Ashley S, Steele D, Ashworth A, Lakhani SR, Smith IE (2006) Basal-like breast carcinomas: clinical outcome and response to chemotherapy. J Clin Pathol 59(7): 729-735

Bertheau P, Turpin E, Rickman DS, Espié M, de Reyniès A, Feugeas JP, Plassa LF, Soliman H, Varna M, de Roquancourt A, Lehmann-Che J, Beuzard Y, Marty M, Misset JL, Janin A, de Thé H (2007) Exquisite sensitivity of TP53 mutant and basal breast cancers to a dose-dense epirubicin-cyclophosphamide regimen. PLoS Med 4(3): e90

Bozzetti C, Musolino A, Camisa R, Bisagni G, Flora M, Bassano C, Martella E, Lagrasta C, Nizzoli R, Personeni N, Leonardi F, Cocconi G, Ardizzoni A (2006) Evaluation of HER-2/neu amplification and other biological markers as predictors of response to neoadjuvant anthracycline-based chemotherapy in primary breast cancer: the role of anthracycline dose intensity. Am J Clin Oncol 29(2): 171-177

Buchholz TA, Tu X, Ang KK, Esteva FJ, Kuerer HM, Pusztai L, Cristofanilli M, Singletary SE, Hortobagyi GN, Sahin AA (2005) Epidermal growth factor receptor expression correlates with poor survival in patients who have breast carcinoma treated with doxorubicin-based neoadjuvant chemotherapy. Cancer 104(4): 676-681

Cardoso F, Piccart MJ (2003) The best use of chemotherapy in the adjuvant setting. Breast 12(6): $522-528$

Carey LA, Dees EC, Sawyer L, Gatti L, Moore DT, Collichio F, Ollila DW, Sartor CI, Graham ML, Perou CM (2007) The triple negative paradox: primary tumor chemosensitivity of breast cancer subtypes. Clin Cancer Res 13(8): 2329-2334

Chan S, Friedrichs K, Noel D, Pintér T, Van Belle S, Vorobiof D, Duarte R, Gil Gil M, Bodrogi I, Murray E, Yelle L, von Minckwitz G, Korec S, Simmonds P, Buzzi F, González Mancha R, Richardson G, Walpole E, Ronzoni M, Murawsky M, Alakl M, Riva A, Crown J, 303 Study Group (1999) Prospective randomized trial of docetaxel versus doxorubicin in patients with metastatic breast cancer. J Clin Oncol 7(8): $2341-2354$

Chevallier B, Roche H, Olivier JP, Chollet P, Hurteloup P (1993) Inflammatory breast cancer. Pilot study of intensive induction chemotherapy (FEC-HD) results in a high histologic response rate. Am J Clin Oncol 16(3): 16223-16228

Colleoni M, Orvieto E, Nolé F, Orlando L, Minchella I, Viale G, Peruzzotti G, Robertson C, Noberasco C, Galimberti V, Sacchini V, Veronesi P, Zurrida S, Orecchia R, Goldhirsch A (1999) Prediction of response to primary chemotherapy for operable breast cancer. Eur I Cancer 35(4): $574-579$

Colleoni M, Viale G, Zahrieh D, Bottiglieri L, Gelber RD, Veronesi P, Balduzzi A, Torrisi R, Luini A, Intra $M$, Dellapasqua $S$, Cardillo $A$, Ghisini R, Peruzzotti G, Goldhirsch A (2008) Expression of ER, PgR, HER1, HER2, and response: a study of preoperative chemotherapy. Ann Oncol 9(3): 465-472 determinant of response and hence these associations should be explored further. Other markers associated with pCR status are also emerging for example, stromal gene signatures (Farmer et al, 2009) and the presence of tumour infiltrating lymphocytes (Denkert et al, 2010). A combined genomic and proteomic analysis on tissue and serum samples obtained sequentially during neo-adjuvant chemotherapy may help define the molecular response pathway, which can be utilised to select the optimal treatment for the individual patient.

\section{ACKNOWLEDGEMENTS}

This study was supported by the Nottingham City Hospital Oncology Research Charitable Fund. The project was approved by the Local Research Ethics Committee and informed consent was obtained for sample collections.

Supplementary Information accompanies the paper on British Journal of Cancer website (http://www.nature.com/bjc)

Denkert C, Loibl S, Noske A, Roller M, Müller BM, Komor M, Budczies J, Darb-Esfahani S, Kronenwett R, Hanusch C, von Törne C, Weichert W, Engels K, Solbach C, Schrader I, Dietel M, von Minckwitz G (2010) Tumor-associated lymphocytes as an independent predictor of response to neoadjuvant chemotherapy in breast cancer. J Clin Oncol 28(1): $105-113$

Desmedt C, Azambuja E, Larsimont D, Rouas G, Di Leo A, Delaloge S, Duhem C, D'Hondt V, Piccart M, Sotiriou C (2009) Predicting the efficacy of anthracyclines in breast cancer (BC) patients: Results of the neoadjuvant TOP trial. J Clin Oncol 27(15s): abstr 523

Di Leo A, Biganzoli L, Claudino W, Licitra S, Pestrin M, Larsimont D (2008) Topoisomerase II alpha as a marker predicting anthracyclines' activity in early breast cancer patients: ready for the primetime?. Eur J Cancer 44(18): 2791-2798

Di Leo A, Larsimont D, Gancberg D, Jarvinen T, Beauduin M, Vindevoghel A, Michel J, Focan CH, Ries F, Gobert PH, Closon-Dejardin MT, Dolci S, Rouas G, Paesmans M, Lobelle JP, Isola J, Piccart MJ (2001) HER-2 and topoisomeraseII alpha as predictive markers in a population of node-positive breast cancer patients randomly treated with adjuvant CMF or epirubicin plus cyclophosphamide. Ann Oncol 12: $1081-1089$

Durbecq V, Paesmans M, Cardoso F, Desmedt C, Di Leo A, Chan S, Friedrichs K, Pinter T, Van Belle S, Murray E, Bodrogi I, Walpole E, Lesperance B, Korec S, Crown J, Simmonds P, Perren TJ, Leroy JY, Rouas G, Sotiriou C, Piccart M, Larsimont D (2004) Topoisomerase-II alpha expression as a predictive marker in a population of advanced breast cancer patients randomly treated either with single-agent doxorubicin or single-agent docetaxel. Mol Cancer Ther 3: 1207-1214

Esteva FJ, Hortobagyi GN (2009) Topoisomerase II $\alpha$ amplification and anthracycline-based chemotherapy: the jury is still out. J Clin Oncol 27(21): $3416-3417$

Faneyte IF, Schrama JG, Peterse JL, Remijnse PL, Rodenhuis S, van de Vijver MJ (2003) Breast cancer response to neoadjuvant chemotherapy: predictive markers and relation with outcome. $\mathrm{Br} J$ Cancer 88(3): $406-412$

Farmer P, Bonnefoi H, Anderle P, Cameron D, Wirapati P, Becette V, André S, Piccart $M$, Campone $M$, Brain $E$, Macgrogan $G$, Petit $T$, Jassem J, Bibeau F, Blot E, Bogaerts J, Aguet M, Bergh J, Iggo R, Delorenzi M (2009) A stroma-related gene signature predicts resistance to neoadjuvant chemotherapy in breast cancer. Nat Med 15(1): $68-74$

Konecny GE, Pauletti G, Untch M, Wang HJ, Möbus V, Kuhn W, Thomssen C, Harbeck N, Wang L, Apple S, Jänicke F, Slamon DJ (2010) Association between HER2, TOP2A, and response to anthracycline-based preoperative chemotherapy in high-risk primary breast cancer. Breast Cancer Res Treat 120(2): 481-489 
MacGrogan G, Rudolph P, Mascarel Id I, Mauriac L, Durand M, Avril A, Dilhuydy JM, Robert J, Mathoulin-Pélissier S, Picot V, Floquet A, Sierankowski G, Coindre JM (2003) DNA topoisomerase IIalpha expression and the response to primary chemotherapy in breast cancer. Br J Cancer 89(4): 666-671

Madjd Z, Pinder SE, Paish C, Ellis IO, Carmichael J, Durrant LG (2003) Loss of CD59 expression in breast tumours correlates with poor survival. J Pathol 200(5): 633-639

Martin-Richard M, Muñoz M, Albanell J, Colomo L, Bellet M, Rey MJ, Tabernero J, Alonso C, Cardesa A, Gascon P, Fernandez PL (2004) Serial topoisomerase II expression in primary breast cancer and response to neoadjuvant anthracycline-based chemotherapy. 66(5): 388-394

Mieog JS, van der Hage JA, van de Velde CJ (2007) Preoperative chemotherapy for women with operable breast cancer. Cochrane database of systematic reviews (Online) 18(2): CD005002

Mieog JS, van der Hage JA, van de Vijuer MJ, van de Velde CJ (2006) Tumor response to preoperative anthracycline-based chemotherapy in operable breast cancer: the predictive role of p53 expression. Eur J Cancer 42(10): $1369-1379$

Miller LD, Smeds J, George J, Vega VB, Vergara L, Ploner A, Pawitan Y, Hall P, Klaar S, Liu ET, Bergh J (2005) An expression signature for p53 status in human breast cancer predicts mutation status, transcriptional effects, and patient survival. Proc Natl Acad Sci USA 102(38): 3550-13555

Nielsen TO, Hsu FD, Jensen K, Cheang M, Karaca G, Hu Z, HernandezBoussard T, Livasy C, Cowan D, Dressler L, Akslen LA, Ragaz J, Gown AM, Gilks CB, van de Rijn M, Perou CM (2004) Immunohistochemical and clinical characterization of the basal-like subtype of invasive breast carcinoma. Clin Cancer Res 10(16): 5367-5374

O'Malley FP, Chia S, Tu D, Shepherd LE, Levine LE, Huntsman DG, Bramwell VH, Andrulis IL, Pritchard KI (2006) Prognostic and predictive value of topoisomerase II alpha in a randomized trial comparing CMF to $\mathrm{CEF}$ in premenopausal women with node positive breast cancer (NCIC CTG MA.5). J Clin Oncol 24(18S): 533

Orlando L, Del Curto B, Gandini S, Ghisini R, Pietri E, Torrisi R, Balduzzi A, Cardillo A, Dellapasqua S, Veronesi P, Viale G, Goldhirsch A, Colleoni M (2008) Topoisomerase IIalpha gene status and prediction of pathological complete remission after anthracycline-based neoadjuvant chemotherapy in endocrine non-responsive Her2/neu-positive breast cancer. Breast 17(5): 506-511

Park JO, Lee SI, Song SY, Kim K, Kim WS, Jung CW, Park YS, Im YH, Kang WK, Lee MH, Lee KS, Park K (2003a) Measuring response in solid tumors: comparison of RECIST and WHO response criteria. Jpn J Clin Oncol 33(10): $533-537$

Park K, Kim J, Lim S, Han S (2003b) Topoisomerase II-alpha (topoII) and HER2 amplification in breast cancers and response to preoperative doxorubicin chemotherapy. Eur J Cancer 39(5): 631-641
Rakha EA, Putti TC, Abd El-Rehim DM, Paish C, Green AR, Powe DG Lee AH, Robertson JF, Ellis IO (2006) Morphological and immunophenotypic analysis of breast carcinomas with basal and myoepithelial differentiation. J Pathol 208(4): 495-506

Rakha EA, El-Sayed ME, Green AR, Lee AH, Robertson JF, Ellis IO (2007) Prognostic markers in triple-negative breast cancer. Cancer 109(1): $25-32$

Rakha EA, Reis-Filho JS, Ellis IO (2008) Basal-like breast cancer: a critical review. J Clin Oncol 26(15): 2568-2581

Rakha EA, Elsheikh SE, Aleskandarany MA, Habashi HO, Green AR, Powe DG, El-Sayed ME, Benhasouna A, Brunet JS, Akslen LA, Evans AJ, Blamey R, Reis-Filho JS, Foulkes WD, Ellis IO (2009) Triple-negative breast cancer: distinguishing between basal and nonbasal subtypes. Clin Cancer Res 15(7): 2302-2310

Rodríguez-Pinilla SM, Sarrió D, Honrado E, Hardisson D, Calero F, Benitez J, Palacios J (2006) Prognostic significance of basal-like phenotype and fascin expression in node-negative invasive breast carcinomas. Clin Cancer Res 12(5): $1533-1539$

Rouzier R, Perou CM, Symmans WF, Ibrahim N, Cristofanilli M, Anderson K, Hess KR, Stec J, Ayers M, Wagner P, Morandi P, Fan C, Rabiul I, Ross JS, Hortobagyi GN, Pusztai L (2005) Breast cancer molecular subtypes respond differently to preoperative chemotherapy. Clin Cancer Res 11(16): $5678-5685$

Sánchez-Muñoz A, García-Tapiador AM, Martínez-Ortega E, DueñasGarcía R, Jaén-Morago A, Ortega-Granados AL, Fernández-Navarro $M$ de la Torre-Cabrera C, Dueñas B, Rueda AI, Morales F, Ramírez-Torosa C Martín-Salvago MD, Sánchez-Rovira P (2008) Tumour molecular subtyping according to hormone receptors and HER2 status defines different pathological complete response to neoadjuvant chemotherapy in patients with locally advanced breast cancer. Clin Transl Oncol 10(10): $646-653$

Schindlbeck C, Mayr D, Olivier C, Rack B, Engelstaedter V, Jueckstock J, Jenderek C, Andergassen U, Jeschke U, Friese K (2010) Topoisomerase IIalpha expression rather than gene amplification predicts responsiveness of adjuvant anthracycline-based chemotherapy in women with primary breast cancer. J Cancer Res Clin Oncol 136: $1029-1037$

Schippinger W, Dandachi N, Regitnig P, Hofmann G, Balic M, Neumann R, Samonigg H, Bauernhofer T (2007) The predictive value of EGFR and HER-2/neu in tumor tissue and serum for response to anthracyclinebased neoadjuvant chemotherapy of breast cancer. Am J Clin Pathol 128(4): $630-637$

Tan DS, Marchió C, Jones RL, Savage K, Smith IE, Dowsett M, Reis-Filho JS (2008) Triple negative breast cancer: molecular profiling and prognostic impact in adjuvant anthracycline treated patients. Breast Cancer Res Treat 111(1): $27-44$ 